\title{
Pacemaker pocket displacement as a symptom of lead dependent infective endocarditis
}

\author{
Przemieszczenie loży stymulatora jako objaw zapalenia wsierdzia \\ zależnego od elektrody
}

\author{
Anna Rydlewska ${ }^{1}$, Andrzej Ząbek ${ }^{1}$, Barbara Małecka ${ }^{1}$, Andrzej Kutarski², Jacek Lelakowski ${ }^{1}$ \\ 'Department of Electrocardiology, Institute of Cardiology, The John Paul II Hospital in Krakow, Jagiellonian University, School of Medicine, \\ Krakow, Poland \\ ${ }^{2}$ Medical University of Lublin, Lublin, Poland
}

\begin{abstract}
We here present a case of lead dependent infective endocarditis which manifested with pacemaker pocket displacement to the left infra mammary region. The patient underwent pacemaker removal without its reimplantation.
\end{abstract}

Key words: lead dependent infective endocarditis, pocket displacement

Kardiol Pol 2013; 71, 9: 960-962

\section{INTRODUCTION}

Pacemaker (PM) infection is a growing problem in clinical practice. It can present in different ways, from local pocket infection to lead dependent infective endocarditis (LDIE).

Diagnosis involves transoesophageal echocardiography (TEE), blood, lead and pocket cultures. The treatment of choice is complete PM removal irrespective of the infection type: this is the only method guaranteeing complete recovery and preventing relapses $[1,2]$.

\section{CASE REPORT}

A female patient aged 37 was admitted to our department due to $\mathrm{PM}$ pocket dislodgement diagnosed in a chest X-ray (Fig. 1).

Anamnesis on admission showed: severe asthma during chronic oxygen therapy, diabetes secondary to chronic systemic steroid therapy treated with insulin, Cushing's syndrome, $3^{\text {rd }}$ grade obesity (BMI 46), lower extremities deep vein thrombosis, right foot ulcer secondary to diabetes mellitus, and VVI implantation in 2000 due to paroxysmal atrio-ventricular $3^{\text {rd }}$ grade block.

In 2007, the patient was admitted to the Intensive Care Unit due to pulmonary embolism. During hospitalisation, the patient underwent vein port removal complicated with wound infection. The port had been implanted to the right

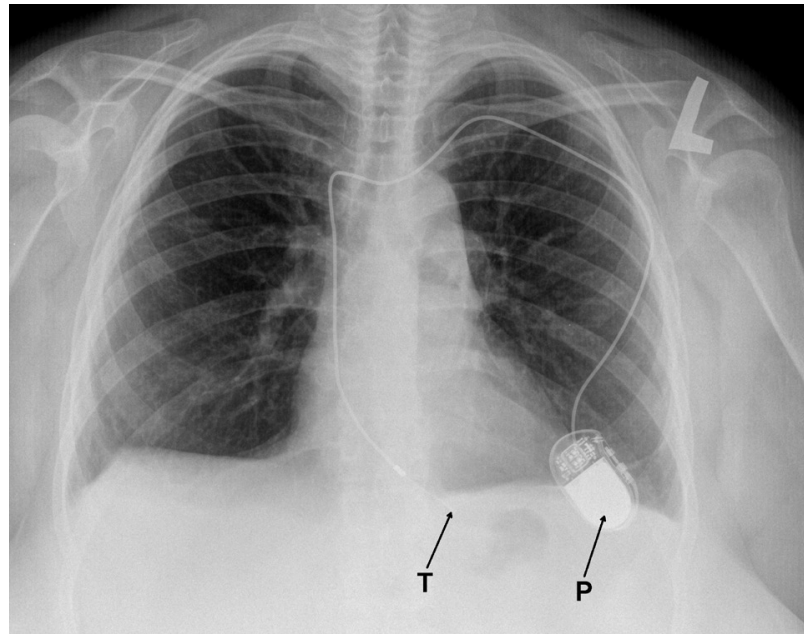

Figure 1. Chest $\mathrm{X}$-ray in PA position. Pacemaker displacement to left infra mammary region; $\mathrm{P}$ — pacemaker; $\mathrm{T}$ — lead tip

subclavian vein in 2005. TEE performed during hospitalisation showed thrombus in the right atrium attached to the lead. The patient was consulted by the cardio surgeon and because of a high operation risk was qualified to conservative treatment. Anticoagulants were administered at this point.

\section{Address for correspondence:}

Anna Rydlewska, MD, Department of Electrocardiology, Institute of Cardiology, The John Paul II Hospital in Krakow, Jagiellonian University, School of Medicine, ul. Prądnicka 80, 30-611 Kraków, Poland, e-mail: annarydlewska@op.pl

Received: 27.02.2012 Accepted: 01.03.2012

Copyright (C) Polskie Towarzystwo Kardiologiczne 


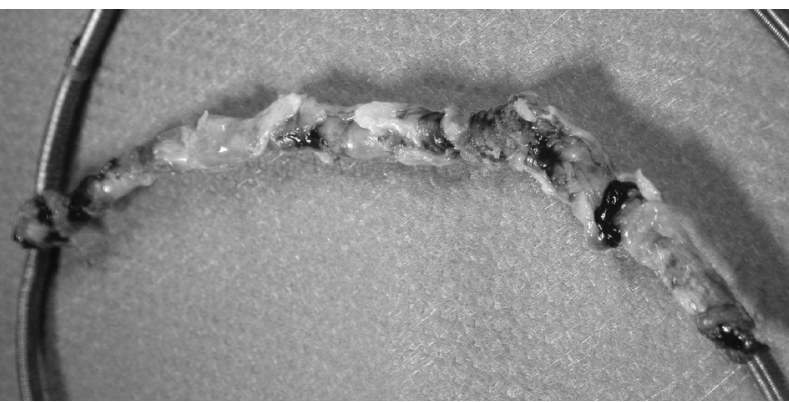

Figure 2. Ventricular lead after extraction. Fibrotic tissue accumulation, neoendothelialisation tunnels and vegetations on the lead surface

In the following three years, the patient was admitted twice to intensive care units due to pulmonary embolism with sepsis. Among pathogens isolated from the air tract were: Serratia marcescens ESBL, methycillin resistant Staphylococcus aureus, and Pseudomonas aeruginosa. More TEEs were performed and a right atrium thrombus was described four more times.

On admission, the patient presented chest discomfort changing with body position of about a month's duration.

Based on the thrombus described in the right atrium (TEE before operation showed a $5 \times 8 \mathrm{~mm}$ structure in contact with the lead), anamnesis of pulmonary embolism and inflammation signs (WBC 14.5, CRP $21.3 \mathrm{mg} / \mathrm{L}$ ), despite negative blood cultures, LDIE was diagnosed. Transvenous lead extraction was performed. Following extraction, the patient was treated with antibiotics (gentamycin, vancomycin). On the surface of the extracted lead, fibrotic tissue creating neoendothelialisation tunnels and vegetations was found (Fig. 2). Blood and tissue cultures were negative. Considering multiple infection risk factors and the anamnesis, the antibiotic therapy was continued for another six weeks. In TEE after the removal, fibrotic residues in the right atrium were described.

Indications for permanent heart stimulation were revised. Considering lack of bradycardia in prolonged Holter-ECG, we decided not to reimplant the PM. The patient was regularly followed-up in an outpatient clinic.

Four months after the procedure, the patient was readmitted to our clinic due to the suspicion of right atrium thrombus presence in ambulatory TEE. Between hospitalisations, she had been in good condition, and had no complaints. Considering her medical history and risk factors, heart magnetic resonance imaging was performed showing only expressed crista terminalis on the posterior wall of right atrium with fatty tissue accumulation. The patient was discharged and is currently being monitored in the outpatient clinic.

\section{DISCUSSION}

The number of electrotherapy complications is growing with the increasing number of cardiac devices implanted. The PM infection rate has been estimated at $0.13-12.6 \%$ [1, 3-5].
Different mechanisms of infection have been described. The main one is infection during the operation, but there have also been described blood transmitted infections from distant locations. In our opinion, the critical moment in which infection might have occurred in our case was the complicated operation of vein port removal seven years after PM implantation. Since that moment, recurrent thrombi in the right atrium along with pulmonary embolism began to be observed.

Another disturbing aspect of this case was the time that had passed from infection to diagnosis and proper treatment. Although the patient had been hospitalised a considerable number of times, she was only once consulted by a cardio surgeon and never by an electrocardiologist.

Numerous co-morbidities, which at the same time are risk factors for infection, might also play a role in our patient's case. We must however underline that every precaution to minimise the risk of infection was taken during the implantation. According to the authors of a Dutch registry based on nearly 50,000 patients, an important factor lowering the risk of infection is antibiotic prophylaxis before the implantation [6]. In our clinic, which is by acknowledged criteria centre performing many implantations, antibiotic prophylaxis is a standard procedure. Also the physician performing implantation, was an experienced operator.

Another noteworthy problem is diagnosis of PM infection despite the lack of classic Duke criteria. These criteria are according to the 2009 guidelines [7] less sensitive for LDIE. Their authors suggest including as major LDIE criteria pulmonary embolism and local lesions of leads or PM. Both criteria were met in our patient's case.

Negative blood and/or PM cultures are described in 23\% of cases, especially in patients who, similar to our patient, received wide spectrum antibiotics before PM removal $[2,7]$.

Another important issue raised by this case is reconsidering the indications for permanent heart stimulation. Both the Dutch and the Mayo registry authors did not reimplant PM after its removal in a significant percentage of patients [6, 8]. Our patient's case is also an example of such a situation. The PM was implanted 11 years before and despite that time it had not yet met ERI criteria. Its recordings show a very low percentage of pacing, and repeated Holter-ECG showed a tendency to a rather fast heart beat.

Considering all of these factors, we decided not to reimplant the PM and to monitor the patient closely in our outpatient clinic.

\section{CONCLUSIONS}

PM infection is a growing problem and LDIE is often diagnosed too late. Vegetation presence on leads in TEE, together with inflammation signs, allows a diagnosis of LDIE. Spontaneous PM pocket dislocation without fibrotic tissue diseases is an indication to begin PM infection diagnosis.

Conflict of interest: none declared 


\section{References}

1. Małecka B, Kutarski A. Lead-dependent infective endocarditis: an old problem, a new name. Cardiol J, 2010; 17: 205-210.

2. Voet JG, Vandekerckhove YR, Muyldermans LL et al. Pacemaker lead infection: report of three cases and review of the literature. Heart, 1999; 81: 88-91.

3. Klug D, Balde M, Pavin D et al. Risk factors related to infections of implanted pacemakers and cardioverter-defibrillators. Results of a large prospective study. Circulation, 2007; 116: 1349-1355.

4. Klug D, Lacroix D, Savoye C et al. Systemic infection related to endocarditis on pacemaker leads. Clinical presentation and management. Circulation, 1997; 95: 2098-2107.
5. Małecka B, Kutarski A, Ząbek A. Skrzepliny, wegetacje, przewlekła zatorowość płucna po implantacji układu stymulującego/kardiowertującego. Folia Cardiol Excerpta, 2009; 4: 96-101.

6. Johansen JB, Jorgensen OD, Moller M et al. Infection after pacemaker implantation: infection rates and risk factors associated with infection in a population-based cohort study of 46299 consecutive patients. Eur Heart J, 2011; 32: 991-998.

7. Guidelines on the prevention, diagnosis, and treatment of infective endocarditis (new version 2009). Eur Heart J, 2009; 30: 2369-2413.

8. Sohail MR, Uslan DZ, Khan AH et al. Management and outcome of permanent pacemaker and implantable cardioverter-defibrillator infections. J Am Coll Cardiol, 2007; 49: 1851-1859. 